\title{
Rhetoric and Reality in Middle Management: The Role of Heads of Academic Departments in UK Universities
}

\section{Jane Creaton and Karen Heard-Laureote}

\begin{abstract}
There is a dissonance between the formal role of head of academic department represented in institutional discourses and the reality of heads' working practices. This paper provides insight, from the perspective of heads, about how the role is experienced and enacted in one institution. Data is derived from twenty semi-structured interviews with heads of department in a teaching focussed university in the UK. The findings show that there is autonomy in how individual heads structure, manage and lead their departments, and so the role is performed in significantly different ways. Nevertheless, for all heads, the development of a clearer institutional mission, vision and strategy had meant that the scope for strategic initiatives at departmental level was more circumscribed and there was a significant issue for many heads about how to make the time and space available for this aspect of the role, given the competing operational demands. Derived from these findings, the paper informs practice by making recommendations about how heads of department may operate more effectively. We suggest that a mesopolitical lens, exploring how social practices are shaped by specific disciplinary and departmental contexts and cultures, may provide a productive perspective on the role of middle leaders and managers.
\end{abstract}

\section{Keywords: heads of department; middle management; organisational culture}

\section{Introduction}

The role of head of academic department $(\mathrm{HoD})$ is central to the effective functioning of a university. In UK universities, the academic department is typically the organisational unit through which courses are organised and delivered, academic staff are recruited and managed, and resources allocated and monitored. The complex and demanding nature of 
the HoD role is reflected in job advertisements which require the ability to combine highly effective strategic leadership with effective operational oversight of the quality of the student learning experience. Some institutions also require applicants to be inspirational researchers of international distinction, to display deep intellectual leadership and vision and/or to have an excellent track record of teaching, planning and income generation. Yet despite the portrayal of the role in many of these advertisements as a senior strategic leader concerned with the high level institutional issues, the reality of the HoD role is often more operational in nature. This dissonance is highlighted by one of the participants in the study presented here: "I think sometimes we are misled about what the role of head is...You suddenly realise you're not that senior in the university, and what your role is, is to firefight all the time..." (HoD 12).

This paper explores how HoDs negotiate the competing operational and strategic demands of the role by providing an insight, from the perspective of HoDs in one institution, about how the role is experienced and enacted. Traditionally, appointments to HoD were temporary and fixed term, rotating among professors and other senior members of the department (Smith, 2007). However, it is increasingly the case, particularly in post 1992 institutions, that HoD posts are longer term management positions. This reflects wider shifts in the higher education (HE) sector. Universities have become increasingly subject to external monitoring and audit, marketization and competition through the Quality Assurance Agency institutional reviews, the Research Excellence Framework, the Teaching Excellence Framework and the forthcoming Knowledge Exchange Framework (Deem, 1998, 2009; Deem et al, 2007; Naidoo, 2005; Naidoo and Williams, 2015). Changes to student finance arrangements, the National Student Survey and league tables have positioned students as consumers in an increasingly competitive marketplace (Locke, 2013; Nixon et al, 2017). The changing national context of $\mathrm{HE}$ and institutional responses to it suggest that the role of HoD has 
become increasingly complex and challenging (Bessant and Mavin, 2016; Floyd and Dimmock, 2011; Jackson, 1999; Stratford, 2012; Waring, 2017).

This article explores the quotidian working practices, decisions and judgements required by a HoD in the current UK HE sector. We begin by drawing on different levels of analysis in $\mathrm{HE}$, to suggest that a meso-level political or mesopolitical lens, provides a productive approach to the study of middle leadership and management. We then review data derived from twenty semi-structured interviews with HoDs in a teaching focussed university in the UK. These findings suggest that there is considerable autonomy in how individual HoDs structure, manage and lead their departments, and so the role is performed and enacted in significantly different ways, even within the same institutional context. Nevertheless, for all HoDs, the development of a clearer institutional mission, vision and strategy had meant that the scope for strategic initiatives at departmental level was more circumscribed and there was a significant issue for many HoDs about how to make the time and space available for this aspect of the role, given the competing operational demands. We conclude with some recommendations about how HoDs might employ some mesopolitical tactics in order to enhance their strategic role within the institution.

\section{Levels of Analysis in HE}

In his framework for thinking about contemporary HE research, Tight (2012) identifies eight different levels of analysis, from the international to the individual. These can be usefully mapped to the macro, meso and micro levels of analysis which are familiar to social scientists (see Table 1). The macro level of analysis tends to focus on national and international $\mathrm{HE}$ trends and the micro on individual students, academics, and the interactions between them at course or group level. The meso level comes between these two levels and in the HE context, can include both the institution and the department. We argue that it is an understanding of this level which is crucial to an analysis of the difficulties faced by HoDs in managing and implementing university strategies at departmental level. 


\section{TABLE 1}

\section{The macro-level}

Macro-level debates in relation to the broader UK HE landscape are never far from the headlines in mainstream media and public discourse. Some of the academic research underpinning these debates, particularly in relation to new public management, is relevant to the leadership and management of universities (Clark, 2001) and specifically to the HoD role. Deem's work on new managerialism, for example, (Deem, 2000, 2006, 2010; Deem et al., 2007) indicated that the UK HE system was becoming more managerial and bureaucratic with traditional notions of collegiality, academic autonomy and professionalism declining. Strategic planning processes which increasingly focus on targets, objective setting and performance indicators may also result in responsibility for institutional strategy and decision making becoming more centralised and top down (Ashworth, 2013).

Some strands of the literature on managerialism are problematic, however, in assuming that all middle managers are captured by corporate discourse. Winter (2009), for example, argues that managerialism has led to a schism in the academic workplace between "academic managers" who have values congruent with managerial discourse and "managed academics" who have values which are not. This oversimplifies both the nature of managerial discourse and how managers are positioned within it. What constitutes "managerialist" or "new public management" or even "neoliberal" discourse is complex and contested. Furthermore, not all academics in all management positions subscribe to some or all "managerialist" values. Many hold personal or political views which may, for example, reject some elements of consumerist discourse in education, whilst still valuing the student voice in departmental and institutional decision making. Although useful, these broader macro accounts of policy shifts on HoDs may underplay the importance of individual agency in mediating these changes. 
The micro-level

Micro level accounts focus on the individual or the course level and although evaluations of innovations in curriculum design, delivery and assessment do appear in HE journals, Tight (2012) suggests that issues of generalisability, identifiability and credibility may reduce the amount of published research at this level. Nevertheless, the use of academic identity as a conceptual framework has foregrounded the micro-level, often from a perspective that locates identity within a wider social context. Henkel's work (Henkel, 2000, 2002, 2005; Henkel and Vabø, 2006), for example, suggests that academic identities are constructed and reconstructed through the dynamic between the individual, the discipline and the institution. Understanding identity as fluid and multiply-constituted also provides a useful frame for understanding the HoD role's different aspects. The "academic" identity can be seen as constructed through the discursive engagement in research, teaching and other scholarly activities, whilst the "managerial" self is produced through managerialist and corporate discourses.

Several authors use the academic identities perspective as a frame for understanding the HoD role. For example, Floyd and Dimmock (2011) argue that the acquisition of a new professional identity associated with the HoD role may marginalise existing academic identities. They suggest that this may lead to role conflicts, and posit a threefold typology based on how HoDs managed these conflicts. The "jugglers" successfully managed their different identities, derived pleasure from their role and were interested in applying for other senior leadership and management positions. The "copers" could just about deal with the role conflicts, and intended to stay in the head role. However, the stresses and strains meant that they did not find their work particularly enjoyable and they tended to keep their professional life increasingly separate from their personal one. Finally, the 'strugglers' were seriously considering stepping down from the role, having found the conflicting demands too difficult and demoralising. Although the experiences of these individuals can be illuminating, 
discussions which do not locate the experience within departmental and disciplinary cultures may be incomplete. Looking at individual typologies may underplay the wider structural factors that shape and limit these individual behaviours and responses.

The missing meso-level

Trowler, Fanghanel and Wareham use the phrase the "missing meso level" $(2005,435)$ to describe the lack of focus on the role of the department or work group in HE research. Noting the paucity of research at departmental level, (Tight, 2012, 216) suggests that focussing on one's own department may be "a risky venture, raising all sorts of issues to do with power, privilege and access". Departmental culture in particular has been relatively neglected and there has been little research on how this "critical unit of analysis in higher education" (Lee, 2007, 42) shapes and is shaped by wider disciplinary and institutional frameworks. It also has a powerful influence in the reproduction and enactment of academic identities with Knight and Trowler $(2001,69)$ describing the department as "the central locus of cultural enactment and, importantly, construction in universities which are, inevitably, extremely culturally complex organisations."

There has, however, been a considerable increase in interest in middle management in $\mathrm{HE}$ in recent years (Branson et al, 2016; Clegg and McAuley, 2005; Davis et al, 2016; Floyd, 2016; Floyd and Dimmock, 2011; Graham, 2016; Waring, 2017). This research identifies the issues involved in reconciling the expectations of senior management teams with local practices, in managing workloads, in leading through persuasion and in reconciling identity schisms and role conflicts. This strand of the literature recognises the limitations of conventional new public management and neoliberal discourses in describing and analysing middle management. Discussions informed by this theoretical framework often portray middle managers as captured by managerialist agendas and primarily motivated by the implementation of top down institutional strategy. Yet in HE the reality is more nuanced and subtle. Clegg and McAuley point to alternative discourses within the academic literature on 
leadership and management which acknowledge the "importance of middle managers in making a significant contribution, albeit somewhat unrecognised by senior management, to radical organisational change" $(2005,20)$.

The research which has focussed specifically on the role of the head of department includes a diverse range of work across institutions, disciplines and jurisdictions (Bryman, 2007; Eley, 2013; Floyd, 2009, 2012; Floyd and Dimmock, 2011; Jackson, 1999; Jones, 2011; Middlehurst, 1993; Smith, 2007; Stanley and Algert, 2007). It has explored HoDs' career motivations and trajectories, the training and preparation received for the role, dealing with people, managing budgets and planning, strategic leadership, effectiveness and identity. However, the very diversity of the contexts and circumstances to which this research relates means that there may be limited value in applying it to other institutional contexts. The role of $\mathrm{HoD}$ is highly contingent on the size, culture and discipline of the department but also on how that department is positioned within the broader institutional framework.

As Knight and Trowler (2001) have indicated, universal, generalist approaches to leadership are essentialist and particularly ill-suited to theorising academic institutional culture. The cultural complexity and diversity at department level means that practices may also vary as much within as across institutions. Their conclusion is that "an analytic focus on leading should use a microscope as well as a telescope" (Knight and Trowler, 2001, 44) and so it is only through the building up of detailed case studies across the sector that leadership and management in HE can be fully explored. This paper responds to this agenda and to the subsequent call from Floyd and Dimmock (2011) to build up a greater picture of institutional variations in how the Head of Department role is situated and enacted. It also intends to highlight and develop the value of the mesopolitical lens in analysing middle management in $\mathrm{HE}$ and illuminating the gap between the rhetoric and the reality of the HoD role.

\section{The Research Study}


The research was undertaken at a post-1992 university, primarily teaching focussed, but committed through its current strategy to enhancing the institution's research and innovation profile. The university generally achieves a middle ranking in university league tables and received a gold rating in the Teaching Excellence Framework. At the time of the study (2015), the University was organised into five faculties containing 29 departments with considerable variation in size, constitution and governance. Academic staff numbers in each department ranged from five to 92 and student numbers from 90 to 1800 . HoDs had traditionally been recruited internally, with each post being for a fixed five-year renewable term. However, a number of HoD posts had recently been advertised externally.

Following the receipt of ethical approval for the project, all $30 \mathrm{HoDs}$ (one department had joint HoDs) were sent an invitation to be interviewed and a participant information sheet. 20 were interviewed, three were unavailable, two refused and five did not respond to the initial email or a follow-up. Table 2 provides information about the sample, broken down by faculty, sex, length of service and size of department. To preserve anonymity, each variable has been presented separately rather than as a combined table. It would have been possible, for example, by cross-referencing sex to length of service and size of department to identify some of the participants. The sample was not intended to be representative, but it did include a very broad cross section of HoDs from each of the faculties, with different sized departments and with a varied length of service in the role.

\section{TABLE 2}

All twenty interviews were carried out between July and September 2015 in participants' offices and took approximately 45 minutes. Participants signed a form to confirm their consent to be interviewed and for the interview to be recorded. The interviews were semistructured and broadly adhered to a list of indicative questions which had been informed by the relevant research literature on HoDs and middle managers. The questions related to five key areas: motivation; relevant experience; preparation, training and support; departmental 
and/or disciplinary context, and advice for new HoDs. Participants were sent this list in advance of the interview, and in some cases, considerable thought had been given to the questions beforehand and the subsequent discussion followed the schedule fairly closely. In others, however, the conversation was far more unstructured. The nature and direction of the earlier interviews informed the subsequent ones and some additional questions were added to the original list. For example, the difficulties of managing email were flagged up at several early interviews and so the later tranche of interviewees were asked specifically about how they handled email within the overall management of their workload.

All the interviews were transcribed verbatim, reviewed for accuracy and then uploaded to NVivo for analysis. Two methods of coding were undertaken in the first cycle. Descriptive coding was used to undertake an initial analysis of the data and to identify key issues in the interviews. Structural coding was then used to link relevant segments of the data with the indicative questions which had framed the interviews. The process combined both a deductive approach (derived from the indicative research questions and the previous research) and an inductive approach (identifying themes which emerged from the interviews with the participants). A second cycle of coding was undertaken to reorganise and analyse the data to produce a higher level list of categories (managing people, managing work, managing resources and managing strategy) which form the organising framework for the findings presented here.

\section{Findings}

The Jarratt Report (1985), which examined the efficiency and effectiveness of management structures within UK universities, recommended clearer definition of HoD duties, responsibilities and lines of accountability. Yet, over 30 years later, the scope or the role remains relatively amorphous within and across institutions. This study's findings are organised according to four key dimensions identified through the analysis of the data: managing people, managing resources, managing work, and managing strategy. These 
align to some extent with Ngyuen's (2012) six broad categories of tasks identified through a review of the literature on academic middle managers: department governance, programme management, human resources (HR) management, budget and resources, external communication and office management. Several of these categories are subsumed within the managing work dimension, which covers how HoDs negotiate both the time management and administrative elements of the role. The additional dimension, managing strategy, was identified in many interviews as a key challenge.

\section{Managing People}

For nearly all of the HoDs in the study, managing people was the most challenging and time consuming aspect of their role and also the one for which they were least prepared. The institution had, with a couple of exceptions, a completely flat academic line management structure. Hence, most HoDs had no prior experience of direct line management, even if they had previously been an associate or deputy HoD.

So you don't actually get the opportunity to get the experience you need for the role and there are a whole host of things that you do as head that you feel, certainly in the early stages, completely unprepared for... (HoD12)

As $\mathrm{HoD}$, they assumed formal line management responsibility for all departmental academic staff (ranging from five to 92). The eight HoDs in departments with more than 40 staff reported that the routine paperwork associated with new appointments, induction, probation, occupational health, sickness and return to work was considerable. Although some of this could be delegated, there were some aspects of line management, such as dealing with underperformance, grievances and claims of bullying and harassment, which the institutional regulations required to be dealt with by the HoD.

...I think it's a massive part of the job. Massive. It can overtake everything. (HoD17)

...the amount of time that HR processes take is just shocking, it works slowly. (HoD6) This was exacerbated in departments with large numbers of academic staff or difficult interstaff relationships. 
When things go wrong that really is where the time is taken up. (HoD2)

It's very time consuming and it takes time away from helping successful staff and staff who are trying to progress their careers. (HoD3)

A HoD with previous line management experience in the private sector found that performance management had been more straightforward there, despite the complication of performance related pay and bonuses:

...the stakes were higher for people really there, because here this isn't really affecting someone's pay or profit, or options share, or options they get. (HoD17) In the private sector there had been quarterly reviews, defined key performance indicators, objectives, structured hierarchies and also very supportive HR department. This was in considerable contrast to the university environment.

It seems to me to be completely different in a university, where you have to pretty much negotiate everything, and people think that they can say no when you say stuff to them. (HoD12)

One head was of the view that that institutional culture and infrastructure militated against any effective performance management:

The elephant in the room is performance management, which most faculties wouldn't touch with a barge pole or, someone once said to me, someone else's barge pole because it's too contentious. (HoD8).

Several HoDs were dissatisfied with the HR department's role and function in supporting performance management. Although HoDs found individual HR team members helpful in providing advice and guidance, there was concern over inadequate institutional infrastructure. HoDs were required to arrange meetings, interviews and to complete the relevant paperwork. This was a concern, not just because of the amount of bureaucracy and the length of the procedures, but because some decisions had legal and financial implications for which some HoDs felt that they lacked the qualifications and training to 
handle. Several HoDs could not understand why difficult and complex cases could not be handed over to qualified HR professionals for investigation:

...in the private sector, by and large, HR would be very, very proactive. The line managers... would just present information to $\mathrm{HR}$, HR would follow it up and thereafter, you know, the line manager might be a witness at some point. (HoD3). Some of those who had gone through difficult processes such as redundancies, managing underperformance or grievances were exhausted, or even traumatised, by the personal and emotional nature of the process. A considerable degree of resilience was needed for dealing with these difficult cases. Nevertheless, one HoD felt that there was a moral and ethical responsibility to tackle these issues:

We are entrusted to act upon that - not just by our employer, but we have to do it on behalf of the people in our departments. (HoD15)

Another frustration for some HoDs was that the amount of time involved in dealing with routine line management and difficult HR cases crowded out the time available to engage in constructive development activities with their staff. A key consideration for HoDs is how to manage performance and development reviews (PDRs) for academic staff. Although the university policy stated that the most appropriate reviewer would normally be the individual's line manager, it also gave a recommended maximum of ten review meetings per cycle. Three incoming HoDs had conducted PDRs with all their staff in their first year of office, but subsequently intended to delegate them to other senior academic staff. However, three HoDs continued to undertake all the reviews themselves, despite the huge time commitment that was involved. They considered this a worthwhile investment because of the opportunity to establish more productive relationships with their staff.

PDRs are critical because I get to know my staff...What I get from that is huge and I think what staff get from that is massive, so it's where I decide to put a lot of effort into. (HoD18) 
Another consideration was that staff might feel short-changed if they did not have a PDR with the HoD, given that other staff had no control over workload and/or resources.

I also know that from the receiving end, when it was delegated out, people weren't taking it seriously unless it was their line manager. (HoD17)

Given these issues, the flat line management structure for academic staff seems unsustainable. Some HoDs had tried to create more hierarchical structures at departmental level within which they could assign day to day task management to senior members of staff. In some cases, having clearly defined roles, responsibilities and expectations within smaller teams had been successful. In others, however, academic staff had insisted on involving the head, as their formal line manager, in all discussions and decisions relating to their day to day workload. This culture of requiring HoD involvement in everything was ingrained in the culture of some departments and was taking some time to change.

...I think it's a culture within this school... people run to the head with the slightest thing. And I spend my life having meetings with people over the things they don't really need to run to the head about, so I'm moving people away from that culture, and I'm about to strengthen the course leaders in terms of the power they have to, again, try to stop all of these low level things coming straight to the head's office when they don't need to. (HoD5)

Despite the centrality of HR function, it did not feature prominently in the advertisements for external HoDs. The issue of managing people provides an excellent example of how important the meso level is to an understanding how HE institutions work in practice. The institutional strategy commits the organisation to ensuring that leaders and managers are able to support, engage and direct their colleagues in their work, performance and development, but the HR infrastructure is set up to provide support to individual HoDs on a one to one basis. The consequence of the decentralised function of the HR department is 
that decisions about whether to deal with poor performance are largely down to the individual HoD's appetite for engaging with the relevant processes.

\section{Managing Work}

The standard contract for a HoD post at this institution allocated 0.8 to the role, with 0.2 for research, scholarship and other related tasks. HoDs struggled to fit their work into the normal working week, with 18 out of the $20 \mathrm{HoDs}$ regularly working beyond the standard working day and/or at weekends:

Where is the balance? Well, there isn't any balance. The point is, it's an endless job. It's one of those ones you could spend 24 hours out of 24 and you wouldn't get through it. (HoD7).

The reality is that it's not a five-day job. I know you shouldn't say that but a 37 hour week is not practical. It's way beyond that. I'm almost saying it's a six-day week, in many cases, and some weeks are even more than that. (HoD8).

There's hardly ever a Sunday I don't work. Sometimes a whole Sunday, sometimes just half a Sunday. Typically, I'm here, you know, I'm typically the last to leave the building. (HoD18)

In addition to HR processes, the HoD's sign off was required on wide range of staff related activities, student related processes, quality and finances.

I am the last port. These are just tiny little micro things that are just endlessly pushed to the heads" (HoD7)

Well, everything comes down to the heads, and I'm sure that's the message you've got from everyone, isn't it? We have to do everything from the irate, angry student, students' parents, staff member with illness, or other issues (HoD18) It's as bad as down to signing flipping eyesight test requests, and working late in the office requests, and getting insurance to drive and work requests, and people going overseas requests. (HoD12) 
HoDs had adopted a range of different strategies to try and manage this workload. One was by reviewing the organisational structure of the department and delegating responsibilities to other academic staff. HoDs did appear to have a significant amount of autonomy in determining these structures, and there were significant differences in how departments were organised, even within the same faculty or within the same size of department. Two faculties were trying to introduce some consistency through the appointment of standard associate head roles with cross departmental responsibilities for education, students and research and innovation. In other departments, responsibilities were delegated to subject area leaders and/or to principal lecturers with cross departmental responsibilities including curriculum, quality, employability, external liaison, resourcing, accreditations and postgraduate research. Some HoDs also had deputies, but not all were formally assigned to that role. However, none of these organisational arrangements enabled any formal delegation of line management responsibilities, with the exception of two departments which had negotiated bespoke arrangements with HR. HoDs who had worked outside the institution found it difficult to understand why staff on well-paid lecturer grades could not be given at least some line management responsibilities, particularly when this was standard for professional staff on much lower grades.

[Principal Lecturers] are supposed to be leadership roles. We tend to develop our staff to make sure they are leading, but apparently they are not allowed to manage... (HoD17)

Much of HoDs' time was also spent trying to manage the huge numbers of emails that they received. They were sent or copied into emails from professional services, faculties, the senior management team and between staff in their department.

I think you just get sandwiched between a lot of people, who are wanting something of you or copying you into it. (HoD10)

A particular bugbear for HoDs was the tendency to be used as a postbox by senior management or for other central services, who sent emails to them for onward circulation. 
HoDs reported getting between at least $100-200$ emails a day and/or spending at least 2 or 3 hours dealing with email every day. Most HoDs also said that they checked their phone or tablet at evenings, weekends and holidays to try and keep the numbers of unread emails under control. This took a considerable personal toll, as evidenced by these two HoDs:

I used to be terrible. I used to all weekend be checking and answering emails continuously, and l'd be doing it at 10 o'clock at night. l'd be doing it last thing, and first thing in the morning when I got up. (HoD 17)

I was...thinking "I'm going to crack" and the only reason is because the email - I can still feel the emotional response that I had at the time, which is you're out of control you cannot do it. (HoD4)

Good administrative support, where available, enabled some HoDs to protect their diary from unscheduled interruptions, but email remained all pervasive and many had been unsuccessful in finding strategies for dealing with it. Very few HoDs delegated their email to an administrator, either because of the sensitivity of some of the emails or because of the perception that staff did not appreciate a reply from a third party. Delegating the management of calendars was more common, at least in terms of organising meetings with other members of staff. In the absence of any institutional management information strategy, HoDs tried to develop personal coping strategies - getting their secretary to filter emails in advance, keeping out of email chains in the hope that a solution could be reached without intervention, prioritising emails from particular people, being ruthless in forwarding emails to other staff or keeping a morning free each week to deal with the backlog.

Previous research (Smith, 2002, 2005) has also indicated that balancing managerial tasks and academic work is a constant struggle for academic managers. The notional allocation of 0.2 of their time to engage in teaching, research or other scholarly activity recognises that the head may want to return to a standard teaching and research contract at the end of their five-year term of office. For most HoDs, however, continuing to engage in teaching and/or research served an equally important function in maintaining credibility with their staff. 
I feel it's important that heads do do those routine duties...so they just don't lose contact. If you haven't taught for five years, you probably haven't got a good idea of what challenges your staff are facing. If you give up research, you probably haven't got much idea of what the demands of research are... (HoD16)

It could also provide powerful leverage with underperforming members of academic staff to be able to show that research and teaching could be maintained alongside the HoD role, even if this meant working at evenings and weekends. At least two HoDs included themselves in the teaching allocation models they used for all staff and with, a couple of exceptions, the other HoDs did at least some teaching, albeit a reduced load.

It was far less common, however, for HoDs to be active researchers. Of the HoDs interviewed, at least five had continued to publish, apply for research grants and be involved in research projects. The majority of HoDs, however, had found the demands of the role to be incompatible with being an active researcher.

There is no way you could do serious research unless you were an established person who could piggyback on others." (HoD20).

This was perhaps, more of a possibility in disciplines where authorship of articles is assigned to the whole research team and a couple of HoDs acknowledged that this was the primary way in which they had been able to maintain a publication record. However, most HoDs took up the role knowing that it was likely to signal the end of their research career. Others still felt it might be possible to return, but were aware that they needed to make a decision soon about whether to become a permanent career track manager.

At the time of the interviews, the advertisement of several external HoD posts had indicated a significant change in institutional expectations regarding the role. Although being a professor was not listed explicitly as one of the essential criteria, the adverts required applicants to have a "distinguished international reputation for published scholarly research", "a proven ability to attract research funding and design" and the ability to "lead and 
coordinate major research projects effectively." In addition, the job descriptions also seemed to suggest that the HoD should also remain an active teacher, requiring "excellence in teaching and course development and the willingness to contribute to a range of teaching programmes, experience of leading the delivery of research programmes, a strong track record of supervising postgraduate research students to successful completion." This may suggest a shift back towards the traditional model of departmental leadership, hitherto more prevalent in the pre-1992 sector, where being a HoD is a shorter term hiatus in an academic career. Nevertheless, it reveals a significant disconnect between institutional rhetoric and departmental reality.

\section{Managing Resources}

There had been a significant change in institutional budgetary processes which had impacted on the role of HoDs. Prior to 2013, financial and planning processes were separate, income was allocated to faculties on a historical cost basis and surpluses could be accumulated from year to year. Deans of faculties had the autonomy to devolve budgets down to HoDs, some of whom had accumulated a considerable amount of resource at departmental level. Under the new resource allocation model, financial and planning processes were brought together, resource allocation was zero based and investment proposals were reviewed on the basis of alignment to institutional priorities. The overall level of surplus (or deficit) generated in each faculty was used to inform (but not determine) decisions on investment proposals.

The new model meant that departments which generated surpluses could no longer make decisions about how the surplus was spent. This had implications for HoDs and how they led and managed their departments. There were mixed views on whether the new system promoted or inhibited entrepreneurialism and initiative at department level. Some departments had done very well out of investment proposals, but other HoDs were concerned that the capacity for responding quickly to opportunities was inhibited by the 
lengthy planning cycle. HoDs were also concerned that a useful management lever had been removed:

...people did use to get money that they could control, through overheads and surpluses of external work that they might have done - research and similar sort of activity...And now, all of this just gets taken by the university...And it's quite hard to keep staff engaging in doing things that will bring in money (HoD13)

In departments which had held significant amounts in purse accounts for staff, there had been considerable resistance to the new process. There was also a concern that the new system had the potential to promote inefficiency. Departments were preparing "blind budgets" with no clear idea how the proposed budget related to actual income and expenditure. It was therefore difficult to see if courses and other activities were cost effective.

\section{Managing Strategy}

Although most HoDs understood and supported the rationale for deploying resources to maximise the strategic benefits at institutional level, they were frustrated at the potential impact on their power and autonomy as a head.

I don't really feel empowered to make financial decisions that count, really. We often joke that we need authorisation to buy a box of paperclips. Unfortunately, it feels like that at times. (HoD2)

At least one head had found a workaround for a funding stream that rewarded staff with small amounts for successful bids, publications and other outcomes which aligned with departmental objectives. Overall, however, it was felt result that the institutional downward pressures had resulted in the HoD role becoming more operational and less strategic. This accords with research in another institution which concluded that "corporate centralisation restricts the ability of departments to operate effectively and, significantly, to respond flexibly to the needs of students" (Waring, 2017, 552). 
It is in relation to managing strategy that some of the tensions between the rhetoric and reality of the HoD role was most evident. HoDs were sceptical about the extent to which there was capacity to be genuinely strategic, given time and institutional constraints.

One view was that the development of a clearer and more centralised mission, vision and strategy had meant that the scope for strategic initiatives at departmental level was more circumscribed. Coupled with the linking of investment proposals to institutional strategic intentions, there was less room for creativity and innovation.

We're more visionary at a central level, which is what a university needs to be, but it makes my job very, very boring now. I would say, in truth, it's not even tactical anymore, it's completely operational. (HoD19)

Other HoDs were not convinced, however, that there had been such a radical transformation in the relationship between centre and departments or in the institutional strategy itself. It's not like we've suddenly become a different creature, we're not. Fundamentally, what we do is what we have always done. The changes are often incremental. (HoD1)

I said, "It's [the new strategic plan] not very different to the old one, is it?" which they weren't amused with, but it's not. (HoD16)

It was acknowledged that some opportunities had been created for departments, including the opportunity to bid for innovative projects from central funds and to carve out new areas of business, such as new courses, partnerships and innovation income. However, these opportunities largely arose in the interstices between institutional policy and departmental discretion and were primarily accessed by the more experienced HoDs. Others found that the opportunity to engage in new strategic developments were crowded out by operational imperatives. When asked about the space available to engage in longer term strategic thinking or planning, several said that they had little or none.

Not a lot, there's just too much stuff. Be it this week on the phone to estates because the sewage is coming up through the toilets. The admin staff have said, "We've 
phoned 10 times, and nobody is coming out." I pick up the phone and they come straight out, but that wasted an hour or two. (HoD6)

But just the relentlessness of the day-to-day, you have to be prepared for that because you never get - well I don't get - quality time, thinking time, proper planning time. (HoD7)

I don't have any time to do it. The day-to-day operational things, what I had absolutely no expectation of is the fact that there is no down time. (HoD11)

These findings support previous research on the struggles faced by middle managers to juggle operational and strategic demands. Deem reported “...long hours packed with meetings, mountains of paperwork and email and the search for additional resources, with research marginalised and little time for reflection" (2000, 4). Bryman and Lilley $(2009,340)$ described HoDs as "people in the middle, stuck between the competing expectations of the centre and their departmental staff' and Winter (2009) identified the frustrations experienced by HoDs in trying to balance research and teaching with the competing demands of managerial tasks. The findings also illustrate a considerable gulf between the visionary leadership role represented in job advertisements and the highly managerial, often operational role performed by most HoDs in the sample. Although the distinction between leadership and management, and strategy and operations can be ambiguous, the data indicates that most of their time was taken up with managerial and operational tasks.

\section{The Mesopolitics of Middle Management}

Despite these findings indicating that HoDs operate under particular institutional, political and structural constraints, they nevertheless have some "scopes of action" which enable them to work within the constraints to achieve particular goals (Willner, 2011). In order to negotiate resources and to promote the interests of their department, the more experienced HoDs engaged in what can be described as micropolitical behaviours. The term "micropolitics" has its origins in organisational research and was originally used by Burns 
(1961) to describe how people use resources to achieve change within organisations. More recently, Lumby (2015) has explored micropolitics in HE leadership, identifying four key strategies: acquiring the support of others, shaping discussions and decisions, creating a favourable impression and weakening opposition. Some of these strategies and tactics were certainly evident in how HoDs managed people, resources, work and strategy within their departments. The more experienced HoDs, in particular, were able to draw on institutional capital acquired over many years within the organisation to build coalitions and networks and influence decision making.

However, it was notable that HoDs had little collective power within the organisation. Coalitions and networks tended to be bilateral, and although HoDs could and did create strategic alliances, these tended to be upwards and downwards rather than horizontally with other HoDs. Despite the hugely important role of the department and the HoD to the success of the institution, they appeared to lack power and influence at the meso level of the organisation: "We are, obviously, emasculated from decision making...there are no heads on Academic Council, and no heads ex officio on senior bodies of the university" (HoD2). Lumby suggests that "micropolitics is the air of organisations" $(2015,8)$, and that preparation and development programmes need to explicitly address the study of power, influence and micropolitical strategies. Yet, we would argue, on the basis of these findings, that mesopolitical strategies are equally important, particularly in institution where strategy and policy is largely driven from the centre.

In this study, individual HoDs had found ways to secure additional funding, handle emails, and make time and space available for the strategic aspects of their role. Yet none of these were effective in addressing the underlying institutional issues about the ineffective distribution of resources, lack of effective HR strategy or the need for a communications policy. To achieve these changes requires HoDs to act collectively to engage explicitly with institutional power and politics at the meso level. Two strategies identified by Lumby (2015) 
in her research on micropolitics - acquiring the support of others and shaping discussions and decisions - provides a useful starting point for considering what might be effective at the meso level. The first strategy, acquiring the support of others, involves tactics such as building coalitions and networks, aligning with more powerful players, and citing support from external experts. In the institution in which the study was located, there were informal and informal HoDs' forums, but these operated largely as sounding boards and discussion groups rather than as an effective lobbying group. Five of the HoDs used the specific terms "whinging" or "whinge-fest" or "whingers" in relation to the forum (HoD1, HoD6, HoD7, HoD12, HoD20). Meetings were simply used to transmit information about institutional strategies, rather than as a mechanism through which to develop and influence policy.

A second strategy identified by Lumby (2015) was shaping discussions and decisions, and included tactics such as consultation, shaping the selection, presentation and circulation of information, influencing committee and meeting membership, meeting agendas and criteria for decision-making. Although some HoDs were familiar with these tactics and had used them to gain influence within their own department, there was little evidence of them being used at the meso level. This was also evident in another study by Graham (2016) who noted that whilst managers were able to make linkages between their macro-political awareness and the internal micro-political agenda, they were less attuned to the internal university politics. Several interviewees felt that if they were to engage meaningfully in strategic planning and implementation, they would need to have a bigger voice in decision making processes in committees and working groups. However, there is a danger that if HoDs did have representation, the absence of a coherent group identity or position would mean that it would be the interests of a specific department being represented rather than the collective interests of HoDs.

This suggests that the power and influence of HoDs as a group can be enhanced through organising and cooperating at the meso level of the organisation. However, the actual 
enactment of this suggestion may be problematic in not accounting for how the meso level is impacted upon by the macro and micro levels of the institution. HE institutions are often structured in ways which hinder, or even obstruct, such cooperation. For example, where institutions have delegated a large degree of autonomy to departments to manage financial affairs or to organise its academic practices, there may be little common interest between different departments or for HoDs to work collectively to challenge the power of the centre. In institutions such as the one in this study, where the institution is highly centralised in its distribution of resources and in how the curriculum is delivered and managed, then there may be more to be gained for collective working.

Other structural barriers remain, however. Firstly, departments may be placed in competition with each other for scarce resources. In the institution in this study, the new resource allocation model required all departments to pool surpluses and then to bid for resources through investment proposals to the centre. Competition was mediated by faculties to some extent, allowing for deficits and surpluses to be pooled across several departments. However, elsewhere in the sector, departments are treated as independent self-sustaining entities which are expected to generate year on year surpluses. In these situations, it may be difficult for HoDs in different financial circumstances to find common ground.

Another barrier to effective cooperative working is the role of the discipline in structuring and influencing academic working practices. Previous research has shown how, for many academics, their discipline may have more influence over their day to day working practices than that of their department (Lee, 2007). This is particularly so for disciplines such as history and maths, which have distinctive theoretical or methodological approaches, broad sharing of assumptions regarding the nature and scope of the discipline and strong professional bodies and associations. In these disciplines, HoDs may identify with their counterparts in other institutions rather than with peers doing the same job in the same institution. This is, perhaps, less of a consideration in departments which include more than 
one discipline or which have a less coherent disciplinary identity (such as criminology or social sciences).

Although these challenges must be recognised and the specific dynamics of the institution accounted for, they are not insurmountable. Even where HoDs have different departmental and or disciplinary interests, they are able to recognise that it important for the role and interests of HoDs to be represented effectively in decision making structures. The challenge is to ensure that representatives on those structures can identify and represent the role and the range of interests, rather than the opportunity to lobby for the interests of a particular department or individual. Secondly, as this research study has shown, there are common interests amongst HoDs which transcend disciplinary and institutional structures. It is in the interests of all HoDs to have effective cross-institutional communication, to tackle unhealthy workloads and to secure institutional backing for the implementation of HE policy and processes.

\section{Conclusions}

The purpose of this article was to explore the dissonance between how the role of head of academic department is represented in institutional discourses and the reality of how the job is performed and enacted by HoDs. The analysis of data from interviews with HoDs in one UK university has suggested that HoDs' approaches to their day to day workload are shaped by institutional strategies and policies and by the distinctive characteristics of their departments. Although within these constraints, HoDs are able to exercise some agency and autonomy, there remain constant tensions between the operational and strategic elements of the role and between the academic and professional aspects of their identity.

Although their role was represented as a key academic leadership position with the university, many HoDs were frustrated by the limited power and influence that they had in the strategic direction of the institution. Whilst there were numerous examples in the data of 
how individual HoDs had resisted or adapted institutional policies and procedures, these micropolitical strategies were of limited value in addressing some of the wider institutional and structural issues which impacted on their role. We concluded that HoDs needed to work together to shape discussions and decisions at the meso level of the organisation. The lack of effective training programmes for middle managers has been noted elsewhere (Floyd, 2009; Sarros et al, 2006; Smith, 2002; Spiller, 2012; Waring, 2017) but these programmes may be equally valuable in creating cohorts and networks which would enable HoDs to work more effectively at the meso level.

This research has provided insights into the role of the HoD in one post 1992 UK HE institution, and the findings are particularly relevant to those institutions where the role of the $\mathrm{HoD}$ is positioned as a longer term management post. However, the findings are of wider relevance to HoDs and to middle managers elsewhere in the HE sector. There is a need for middle managers to be aware of the need to work collectively to establish power and influence in institutional decision making across the institution. Despite the challenges outlined, there is the potential for HoDs to be positive, strategic and entrepreneurial with the capacity to create change and transformation from within organisations. For example, recent work on changing academic work and careers in the UK (Locke et al, 2016; Whitchurch \& Locke, 2016) has noted the critical importance of middle managers in interpreting institutional policies locally. The relationships that middle managers establish can have a transformational function in enabling policies and initiatives to be facilitated across all levels of the institution.

\section{References}

Ashworth, R., Ferlie, E., Hammerschmid, G., Moon, M. J., and Reay, T. (2013) 'Theorizing Contemporary Public Management: International and Comparative Perspectives', British Journal of Management 24: S1-S17.

Bessant, C., and Mavin, S. (2016) 'Neglected on the front line: Tensions and challenges for 
the first-line manager-academic role in UK business schools', Journal of Management Development 35(7): 916-929.

Branson, C. M., Franken, M., and Penney, D. (2016) 'Middle leadership in higher education: A relational analysis', Educational Management Administration and Leadership 44(1): $128-145$.

Bryman, A. (2007) 'Effective leadership in higher education: a literature review', Studies in Higher Education 32(6): 693-710.

Bryman, A., and Lilley, S. (2009) 'Leadership researchers on leadership in higher education', Leadership 5(3): 331-346.

Burns, T. (1961) 'Micropolitics: Mechanisms of institutional change', Administrative Science Quarterly 6(3): 257-281.

Clark, B. (2001) 'The entrepreneurial university: New foundations for collegiality, autonomy, and achievement', Higher Education Management 13(2): 9-24.

Clegg, S., and McAuley, J. (2005) 'Conceptualising middle management in higher education: A multifaceted discourse', Journal of Higher Education Policy and Management 27(1): 19-34.

Davis, A., Jansen van Rensburg, M., and Venter, P. (2016) 'The impact of managerialism on the strategy work of university middle managers', Studies in Higher Education 41(8): $1480-1494$.

Deem, R. (1998) "'New managerialism" and higher education: The management of performances and cultures in universities in the United Kingdom', International Studies in Sociology of Education 8(1): 47-70.

Deem, R. (2000) 'New Managerialism' and the management of UK universities. End of Award Report of the Findings of an ESRC Funded Project, Lancaster: Lancaster University.

Deem, R. (2006) 'Changing Research Perspectives on the Management of Higher Education: Can Research Permeate the Activities of Manager-Academics?', Higher Education Quarterly 60(3): 203-228. 
Deem, R. (2009) 'Leading and managing contemporary UK Universities: Do excellence and meritocracy still prevail over diversity?', Higher Education Policy 22(1): 3-17.

Deem, R. (2010) 'Herding the academic cats; The challenges of 'managing' academic research in the contemporary UK university', Perspectives: Policy and Practice in Higher Education 14(2): 37-43.

Deem, R., Hillyard, S., and Reed, M. (2007) Knowledge, Higher Education, and the New Managerialism: The Changing Management of UK Universities, Oxford: Oxford University Press.

Eley, A. (2013) 'Management Training for the University Head of Department', International Journal of Educational Management 8(2): 20-22.

Floyd, A. (2009) Life histories of academics who become Heads of Department: socialisation, identity and career trajectory, Leicester: University of Leicester.

Floyd, A. (2012) "'Turning Points" The Personal and Professional Circumstances That Lead Academics to Become Middle Managers', Educational Management Administration and Leadership 40(2): 272-284.

Floyd, A. (2016) 'Supporting academic middle managers in higher education: do we care?', Higher Education Policy 29(2): 167-183.

Floyd, A., and Dimmock, C. (2011) ' "Jugglers", "copers" and "strugglers": academics' perceptions of being a head of department in a post-1992 UK university and how it influences their future careers', Journal of Higher Education Policy and Management 33(4): 387-399.

Graham, A. (2016) 'Role of academic managers in workload and performance management of academic staff', Educational Management Administration and Leadership 44(6): 1042-1063.

Henkel, M. (2000) Academic Identities and Policy Change in Higher Education, London: Jessica Kingsley.

Henkel, M. (2002). 'Academic Identity in Transformation?', Higher Education Management and Policy 14(1): 137-147. 
Henkel, M. (2005) 'Academic identity and autonomy in a changing policy environment', Higher Education 49(1): 155-176.

Henkel, M., and Vabø, A. (2006) 'Academic identities', in M. Kogan, M. Henkel, M Bauer and I. Bleiklie (eds). Transforming Higher Education, Heidelberg: Springer, pp. 127-159. Jackson, M. P. (1999) 'The role of the head of department in managing performance in UK universities', International Journal of Educational Management 13(1): 142-155.

Jarratt, A. (1985) Report of the steering committee for efficiency studies in universities, London: Committee for Vice Chancellors and Principals.

Jones, D. (2011) 'Academic Leadership and Departmental Headship in Turbulent Times', Tertiary Education and Management 17(4): 279-288.

Knight, P., and Trowler, P. (2001) Departmental Leadership In Higher Education, Milton Keynes: Open University Press.

Lee, J. (2007) 'The shaping of the departmental culture: Measuring the relative influences of the institution and discipline', Journal of Higher Education Policy and Management 29(1): 41-55.

Locke, W. (2013) 'The Intensification of Rankings Logic in an Increasingly Marketised Higher Education Environment', European Journal of Education 49(1): 77-90.

Locke, W., Whitchurch, C., Smith, H., and Mazenod, A. (2016) Shifting landscapes: Meeting the staff development needs of the changing academic workforce, York: Higher Education Academy.

Lumby, J. (2015) In the wings and backstage: exploring the micropolitics of leadership in higher education. Research report, London: Leadership Foundation for Higher Education.

Middlehurst, R. (1993) Leading academics, Buckingham: SRHE and Open University Press. Naidoo, R. (2005) 'University in the Marketplace: The Distortion of Teaching and Research', in R. Barnett (ed), Reshaping the university: new relationships between research, scholarship and teaching, Maidenhead: Open University Press, pp. 27-36.

Naidoo, R., and Williams, J. (2015) 'The neoliberal regime in English higher education: 
charters, consumers and the erosion of the public good', Critical Studies in Education 56(2): 208-223.

Nguyen, T. L. H. (2012) 'Middle-level Academic Management: A case study on the roles of the Heads of Department at a Vietnamese university', Tertiary Education and Management 19(1): 1-15.

Nixon, E., Scullion, R., and Hearn, R. (2017) 'Her majesty the student: marketised higher education and the narcissistic (dis)satisfactions of the student-consumer', Studies in Higher Education 43(6): 927-943.

Sarros, J. C., Gmelch, W. H., and Tanewski, G. A. (2006) 'The Role of Department Head in Australian Universities: Tasks and Stresses', Higher Education Research and Development 16(3): 283-292.

Smith, B. (2007) 'On being a university head of department', Management in Education 21(1): 4-7.

Smith, R. (2002) 'The Role of the University Head of Department: A Survey of Two British Universities', Educational Management Administration and Leadership 30(3): 293-312.

Smith, R. (2005) 'Departmental Leadership and Management in Chartered and Statutory Universities: A Case of Diversity', Educational Management Administration and Leadership 33(4): 449-464.

Spiller, M. (2012) Learning to manage or managing to learn: an exploratory study of how university managers learn within their roles, Stoke on Trent: Staffordshire University.

Stanley, C., and Algert, N. (2007) 'An exploratory study of the conflict management styles of department heads in a research university setting', Innovative Higher Education 32(1): 49-65.

Stratford, E. (2012) 'A genuine career or impossible heroism? Experiencing the role of the Head of School: an Australian case study', Journal of Higher Education Policy and Management 34(3): 225-238.

Tight, M. (2012) Researching Higher Education (2nd ed.), Maidenhead: McGraw-Hill Education. 
Trowler, P., Fanghanel, J., and Wareham, T. (2005) 'Freeing the chi of change: the Higher Education Academy and enhancing teaching and learning in higher education', Studies in Higher Education 30(4): 427-444.

Waring, M. (2017) 'Management and leadership in UK universities: exploring the possibilities of change', Journal of Higher Education Policy and Management 39(5): 540-558.

Whitchurch, C., and Locke, W. (2016) The implications of a changing academic workforce for the university as a critical institution. Paper presented at the Consortium of Higher Education Researchers 29th Annual Conference; 5-7 September,Cambridge, UK.

Willner, R. (2011) 'Micro-politics: an underestimated field of qualitative research in political science', German Policy Studies 7(3): 155.

Winter, R. (2009) 'Academic manager or managed academic? Academic identity schisms in higher education', Journal of Higher Education Policy and Management 31(2): 121-131. 
Table 1: Situating Tight's (2012) levels of analysis within a macro, meso and micro level frame.

1. International, involving consideration of two or more MACRO LEVEL ANALYSIS national systems

2. System or idealized arrangement of HE

3. Nation or Country

4. Region (part of a country, or a group of institutions)

5. Institution, University or College MESO LEVEL ANALYSIS

6. Department or Centre or Group of Academics and Students

7. Course or Group of Students and their Teachers MICRO LEVEL ANALYSIS

8. Individual, Student or Academic 
Table 2: Information about the Participants

By Faculty

\begin{tabular}{lllll}
\hline Faculty A & Faculty B & Faculty C & Faculty D & Faculty E \\
\hline 4 & 3 & 5 & 3 & 5
\end{tabular}

By Gender

\begin{tabular}{ll}
\hline Male & Female \\
\hline 13 & 7 \\
\hline
\end{tabular}

By Length of Service

\begin{tabular}{lll}
\hline $\mathbf{0 - 5}$ years & $\mathbf{6 - 1 0}$ years & $\mathbf{1 1 + \text { years }}$ \\
\hline 10 & 8 & 2 \\
\hline
\end{tabular}

By Size of Department

\begin{tabular}{lll}
\hline $\mathbf{1 - 3 0}$ & $31-60$ & $\mathbf{6 1 +}$ \\
\hline 7 & 10 & 3
\end{tabular}

